\title{
Pain Study in X-Linked Adrenoleukodystrophy in Males and Females
}

\author{
Valeria Bachiocco $\cdot$ Marco Cappa · Anna Petroni · Ettore Salsano • \\ Carla Bizzarri · Ilaria Ceccarelli · Gabriele Cevenini · Viviana Pensato • \\ Anna M. Aloisi (D)
}

Received: December 3, 2020 / Accepted: February 8, 2021 / Published online: February 20, 2021

(c) The Author(s) 2021

\begin{abstract}
Introduction: X-linked adrenoleukodystrophy (ALD) is a metabolic disorder in which very long chain fatty acids (VLCFAs) are accumulated in the nervous system and adrenal cortex, impairing their functions. Three main variants are described in males: adrenomyeloneuropathy $(\mathrm{AMN})$, a cerebral form (CALD or cAMN) and Addison's disease only (AD), while for females no classification is used. To evaluate pain and the functional state of afferent fibers, a series of
\end{abstract}

Supplementary Information The online version contains supplementary material available at https:// doi.org/10.1007/s40122-021-00245-0.

V. Bachiocco - A. Petroni - I. Ceccarelli ·

A. M. Aloisi $(\square)$

Department of Medicine, Surgery and Neuroscience,

University of Siena, Siena, Italy

e-mail: Annamaria.aloisi@unisi.it

M. Cappa · C. Bizzarri

Bambino Gesù Children's Hospital, IRCCS, Rome, Italy

A. Petroni · A. M. Aloisi

Biomedicine and Nutrition Research Network,

Milan, Italy

E. Salsano $\cdot$ V. Pensato

IRCCS C. Besta Neurological Institute Foundation,

Milan, Italy

G. Cevenini

Department of Medical Biotechnology, University

of Siena, Siena, Italy tests was carried out in male and female patients.

Methods: Chronic pain occurrence and sensory phenotype profile were assessed in 30 patients (20 male: 10 AMN, 1 cAMN, 1 cALD, 8 AD; and 10 female). A set of instruments assessed the intensity, quality and extent of pain, while a battery of quantitative sensory testing (QST) procedures examined the functional status of $\mathrm{A} \beta$ and $\mathrm{A} \delta$ fibers. Principal component analysis and hierarchical clustering with sensory responses input were used to identify distinct clusters.

Results: Nearly half of the subjects reported pain, with a high prevalence in females and male AMN patients. No sex differences in pain dimensions were found. The sensory responses were heterogeneous, differing among the clinical variants and between genders. Male AMN/ cAMN/CALD patients showed the worst impairment. $A \beta$ and $A \delta$ fibers were affected in males and females, but $\mathrm{A} \beta$ fibers appeared undamaged in females when tactile sensitivity was tested. Abnormal responses were localized in the lower body district, according to the dying-back pattern of the neuropathy. Cluster analysis showed discrete clusters for each function examined, with well-interpretable sensory and clinical phenotypes.

Conclusion: The study of pain and of the sensory profile appears to indicate a difference in the mechanisms underlying the AMN/cAMN/ cALD and $\mathrm{AD}$ clinical forms and in the 
treatment of the respective generated pain types.

Keywords: ALD; Pain; QST; Sex differences

\section{Key Summary Points}

Why carry out this study?

Adrenoleukodystrophy (ALD) is an $\mathrm{X}$-linked disorder mostly affecting the nervous system and adrenal cortex, often giving rise to chronic pain. Nevertheless, pain studies on ALD patients are rare.

It was hypothesized that administering specific questionnaires and sensory testing (QST) would highlight characteristics of the pain phenotype and mechanisms.

\section{What was learned from the study?}

Pain prevailed in females and AMN (adrenomyeloneuropathy) subjects; $\mathrm{A} \beta$ and $A \delta$ fibers responded differently in the neural forms and the Addison's variant and in males with respect to females, all aberrant responses being located in the lower limbs.

Pain and sensory phenotype varied based on the primary pathological disorder mechanisms, localization and gender.

\section{DIGITAL FEATURES}

This article is published with digital features, including a summary slide, to facilitate understanding of the article. To view digital features for this article go to https://doi.org/10.6084/ m9.figshare.13721440.

\section{INTRODUCTION}

Adrenoleukodystrophy (ALD) is an X-linked inherited metabolic disease caused by mutations in the ATP-binding cassette (ABC) transporter subfamily $\mathrm{D}$ member 1 gene (ABCD1) which encodes for a peroxisomal transmembrane protein involved in the transport of very long chain fatty acids (VLCFA) from cytosol into peroxisomes, where they undergo $\beta$-oxidation $[1,2]$. Abnormal accumulation of VLCFA is ubiquitous, but the nervous system, adrenal cortex and testis are mainly affected $[1,3]$. The excess of VLCFA and the development of molecular and metabolic alterations cause different functional impairment in the tissues, and the downstream mechanisms dictating the signature and severity of the disease are still largely unclear [4-7]. The clinical phenotype is heterogeneous, although three major variants have been described. Addison's disease only (AD) is characterized by decreased cortisol production and release, and thus by adrenal insufficiency [8, 9]. Adrenomyeloneuropathy (AMN) involves a progressive axonopathy affecting sensory ascending and motor descending spinal tracts as well as peripheral nerves, which causes sensory and motor disturbances $[5,6,8]$. Cerebral adrenoleukodystrophy (cALD), or cerebral adrenomyeloneuropathy (cAMN), is marked by myelin destabilization and serious neuroinflammation $[1,5,6,8]$, giving rise to severe cognitive, behavioral and neurological dysfunctions. Sixty-six percent of AMN patients present adrenal involvement [8], while 35\% $[10,11]$ progress towards an overt cerebral inflammatory form.

Signs and symptoms of the disease have been described in males and also in females, so-called carriers. Nevertheless, depending on the studies, $50 \%$ or more of such women present some neurological anomaly, $57 \%$ manifest a peripheral neuropathy and 63\% develop a late progressive myelopathy $[12,13]$. Both large and small nerve fiber dysfunction has been described in AMN-like females $[8,14]$ and in AMN males [15-17]. The changes involving the sensory system are frequently accompanied by pain, defined as neuropathic due to the injury or disease affecting the neural structures [18].

Quantitative sensory testing (QST) was developed to study different aspects of the sensory system. Stimuli with defined properties are administered and the quality and 
magnitude of the evoked responses are analyzed $[19,20]$ in order to ascertain the functional status of the activated neural pathway, the occurrence of any sensory disturbance and its localization. This procedure also identifies signs of plus or minus sensory functioning, i.e. hyperesthesia and hypoesthesia. Based on these characteristics, QST has been used in various clinical conditions [21-24]. The clinical features of the neural variants (AMN/CAMN/cALD) of the disease consist of a progressive impairment of nervous system functions, with both central and peripheral damage. Although an objective description of the sensory profile would enable a better definition of the pathology, its time course and body distribution pattern, we are unaware of studies in which a systematic sensory investigation has been performed.

The aim of the present study on X-ALD subjects was to evaluate pain and the functional state (correct functioning or disturbance) of afferent fibers in well-defined body areas. Particular attention was given to the presence of latent or subclinical dysfunctions in the female "carriers" and the body distribution of these dysfunctions.

\section{METHODS}

\section{Subjects and Experimental Procedures}

The study enrolled biochemically and genetically proven ALD patients (20 male and 10 female) regularly followed up at the Bambino Gesù Children's Hospital (Rome, Italy) and the IRCCS C. Besta Neurological Institute Foundation (Milan, Italy). Selection of subjects was random among patients who complied with the study protocol. The study adhered to the Declaration of Helsinki and was approved by the local ethics committees of the Bambino Gesù Children's Hospital and the IRRCS C. Besta Neurological Institute Foundation; all the patients and their parents or guardians gave their written informed consent to use their clinical data in anonymized form (Mod.CUP_02consinf_15/07/ 2003 and subsequent amendments).

Male patients were divided into the following clinical forms: adrenomyeloneuropathy
$(\mathrm{AMN})$, cerebral AMN (cAMN), cerebral adrenoleukodystrophy (cALD) and Addison's disease only (AD). The criteria used for the classification of the patients with neurological symptoms (i.e. AMN, cAMN and cALD patients) were based on clinical and MRI findings, in agreement with previous classification [25, 26]. Patients were considered as AD when they had adrenal failure only, and no anti-adrenal antibody was detectable [27]. Adrenal failure was considered when ACTH plasma levels were higher than $65 \mathrm{pg} / \mathrm{ml}$ and morning cortisol levels lower than $14 \mathrm{mcg} / \mathrm{dl}$ [3]. Female patients included both symptomatic and asymptomatic cases, as indicated in Table 1. A female was considered symptomatic when she had any neurological symptom/sign compatible with the diagnosis of ALD, including progressive spastic paraparesis, sensory deficits and bladder dysfunction [12].

The evaluation session lasted about $2 \mathrm{~h}$. In all male and female subjects, a semi-structured interview was conducted to determine the clinical status, disease onset and evolution; the patient's past (during the last 3 months) and present pain, the pain intensity and quality, and its extension and distribution were estimated by means of specific instruments, respectively, visual analog scale (VAS), Italian Pain Questionnaire (QUID) and Margolis Pain Diagram. A quantitative sensory testing (QST) battery was used to assess thermal and tactile sensitivity and measure mechanical (painful, non-painful, superficial and deep) thresholds, intensity of evoked pain and their distribution in the upper and lower parts of the body. The wind-up test was also applied by means of the von Frey filament method to evaluate the excitability of the CNS.

\section{Instruments and Measurements}

\section{Visual Analog Scale (VAS)}

VAS is a $10-\mathrm{cm}$ horizontal line bounded at the extremes by "no pain" and "worst pain possible" which measures the intensity of pain $(0-10)$. Subjects were asked to place a cross on the horizontal line at the point that represented the highest pain intensity perceived. 


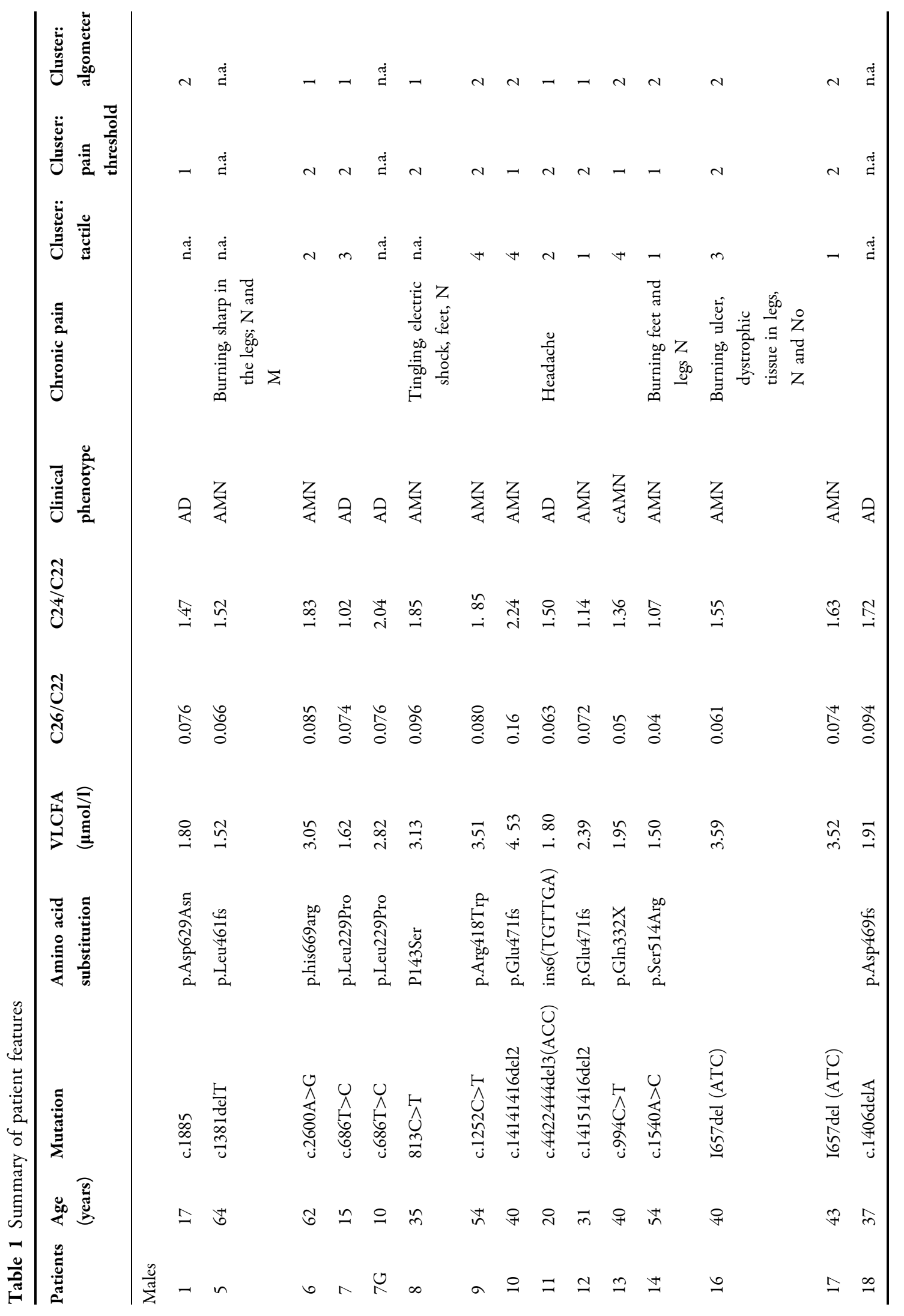




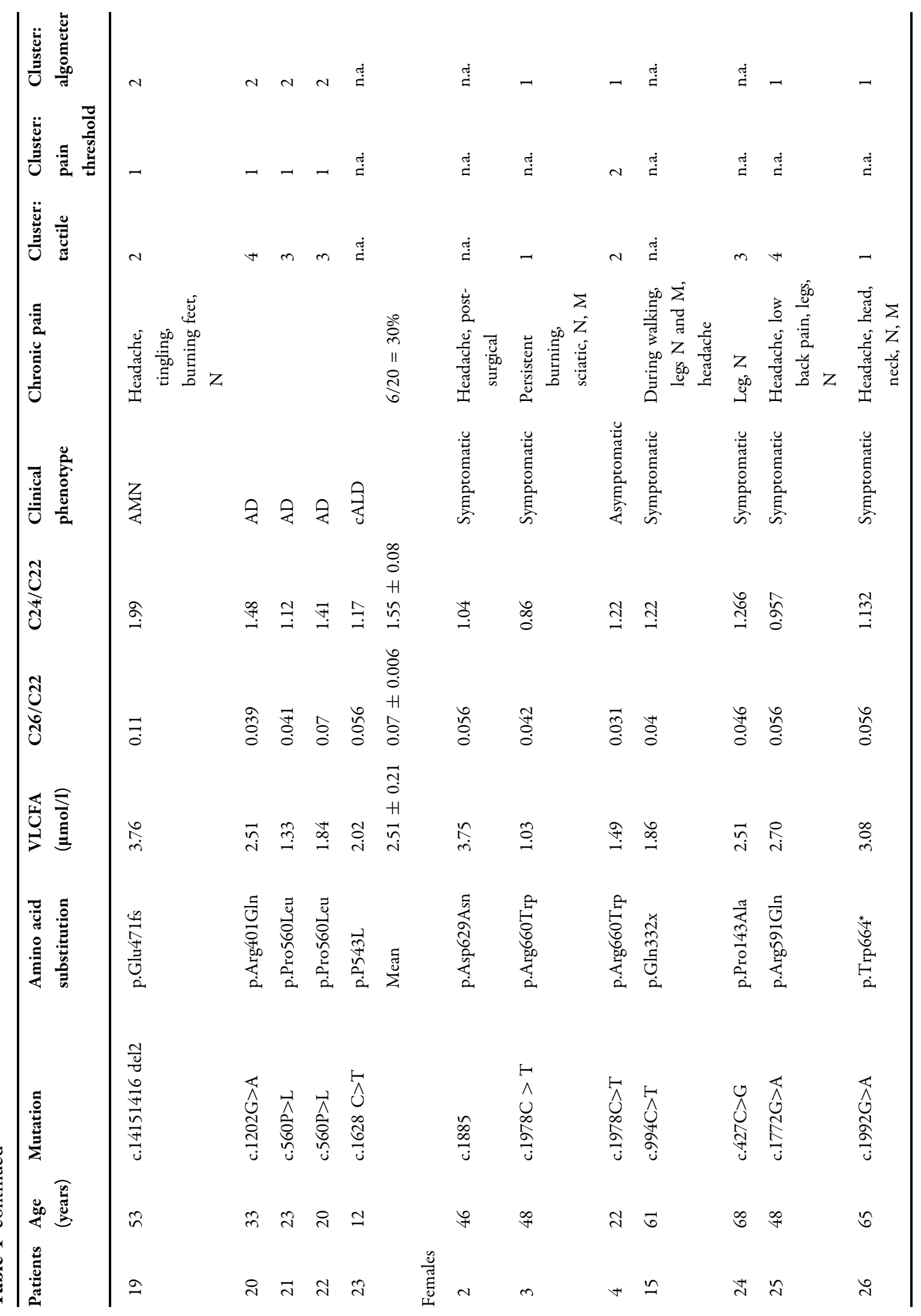




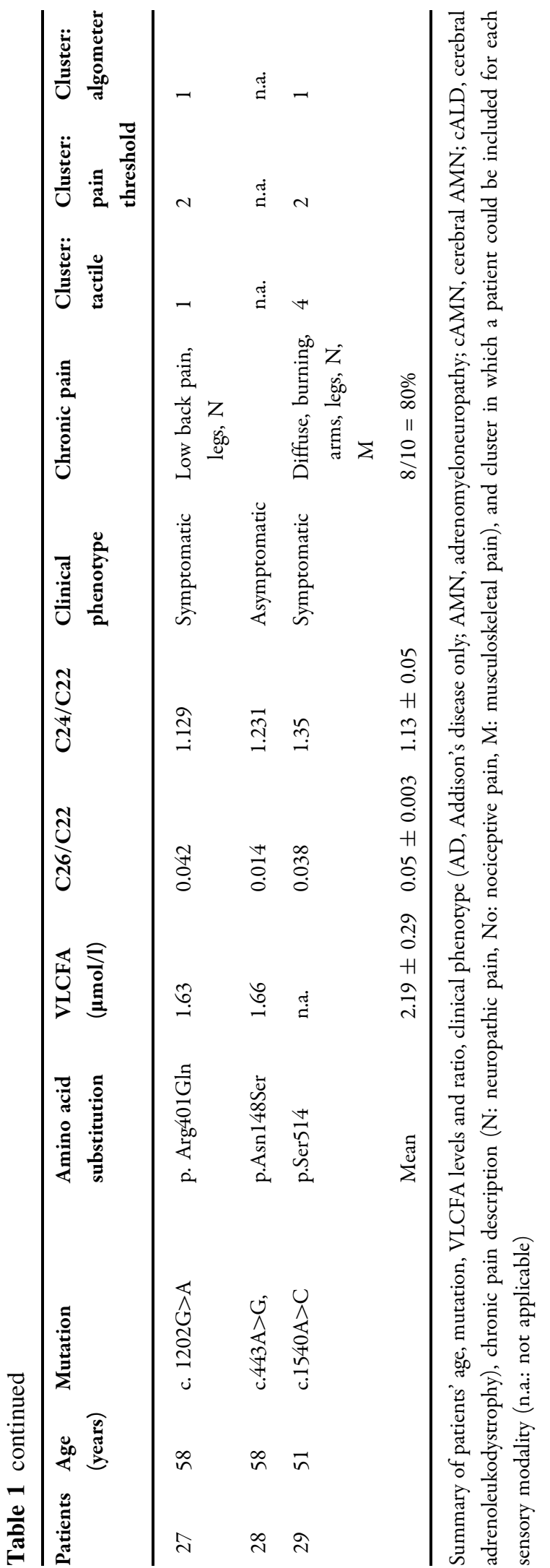

The Italian Pain Questionnaire (QUID)

QUID [28] estimates the quality and intensity of pain. It is a semantic interval scale consisting of 42 descriptors divided into four main classes: sensory, affective, evaluative, miscellaneous. The Pain Rating Index rank value (PRIr) for each dimension and for the whole experience (Pain Rating Index rank-Total-PRIr-T) is given by the sum of scores each descriptor represents. The instrument also incorporates a five-point adjective scale to measure the present pain intensity (PPI) (0-5).

\section{Margolis Pain Diagram}

The Margolis pain diagram [29] weights the extension and distribution of pain, expressed as the percentage of body surface in pain and its location. The tool consists of a dorsal and a ventral drawing of the body. The subjects are asked to shade areas in which they have experienced pain.

\section{Quantitative Sensory Testing (QST)}

Six modalities of stimulation, both innocuous (i.e. thermal, light tactile sensation, mechanical detection threshold) and noxious (i.e. mechanical pain threshold, pressure pain threshold), were administered. Moreover, the wind-up phenomenon was tested in all patients.

In particular:

- The thermal test was performed by letting a drop of acetone fall on each body point [30]. An approximately $50 \mu \mathrm{l}$ drop of room temperature acetone (Zeta Farmaceutici, Vicenza, Italy) was applied from a $1 \mathrm{ml}$ syringe.

- Light tactile test was carried out by gentle brushing with cotton wool along $2 \mathrm{~cm}$ of the skin at each point $[19,20]$.

- The mechanical detection threshold (MDT) was determined using a standardized set of von Frey filaments (Semmes Weinstein, Stoelting Co.) exerting forces from 0.078 to $588.235 \mathrm{mN}$ (size $1.65-5.88$ ), the contact area of the probe being uniform and flat. Each filament was applied to the skin in ascending order at a $90^{\circ}$ angle with sufficient force to bend or bow the filament and was held in place for $1.5 \mathrm{~s}$ and then removed. 
Patients were instructed to indicate when a stimulus was felt $[19,20]$.

- The mechanical pain threshold (MPT) was assessed using von Frey filaments (Semmes Weinstein, Stoelting Co.) exerting forces from 980.392 to $2941.176 \mathrm{mN}$ (size 6.10-6.65), purposely modified (the contact area was reduced to $0.2 \mathrm{~mm}$ diameter) to induce pain. Filaments were applied to the skin in ascending order until the first perception of pain was reached. The patient's sensitivity to the pinprick pain was evaluated by considering the applied force $(\mathrm{mN})$ and the intensity of pain perceived (VAS 0-10) $[19,20,31]$.

- The pressure pain threshold (PPT) was performed with a graded algometer (Forced Dial FDK 20, Wagner Instruments, Greenwich, CT, USA) whose probe area was exerting a pressure up to $10 \mathrm{~kg}$. The measurement was stopped when the subject indicated that the stimulus became painful or when the pressure reached $5 \mathrm{~kg}$. The patient's sensitivity to the pressure pain was assessed by reporting the applied force $(\mathrm{kg})$ and the intensity of pain perceived (VAS 0-10) $[19,20,31]$.

- Wind-up test. A single pinprick stimulus whose force was equal to the value found in the MPT test was administered on an area of $1 \mathrm{~cm}^{2}$ on the volar surface of the nondominant arm, after which a series of 10 stimuli was applied at $1 / \mathrm{s}$ rate $[19,20]$. The wind-up magnitude was calculated as the difference between the intensity of pain evoked by the single stimulus (VAS 0-10) and the pain intensity elicited over the whole series [32].

A trained investigator (VB) administered the QST battery in a quiet environment with the patient lying quietly. Tests were always given in the same order, as reported above, and the researcher waited $30 \mathrm{~s}$ between tests to avoid temporal summation. QST was performed within all body areas (e.g. trunk, upper and lower extremities). Twenty body points (10 per side symmetrically located on the right and left, Fig. 1) were tested starting from the upper part of the body and moving to the feet [33]. The subjects had to report the sensation felt when the stimulus was applied.

Prior to the sensory testing, subjects were informed about the procedure and the ability to stop it at any time.

\section{Statistical Analysis}

The descriptive analysis was carried out on all subjects. Data are reported as mean \pm SEM. The normal distribution of the data was verified by the Kolmogorov-Smirnov test. Comparisons were performed with one-way analysis of variance (ANOVA) with the factor Sex (two levels: male, female) or the factor Group (two levels: AD males, AMN/cAMN/cALD males) depending on the measures to be analyzed.

For each QST determination, an agglomerative hierarchical cluster analysis was used with a between-group average linkage aggregation technique to identify clusters of patients with homogeneous characteristics. In the agglomerative hierarchical clustering, the analyzed $\mathrm{N}$ statistical units were joined together iteratively, starting with $\mathrm{N}$ clusters, each consisting of a single unit and ending with a single cluster. The Euclidean distance was used to determine the distance between pairs of elements. Pearson correlation, which measures the degree of linear relationship between two profiles, was applied. The average linkage clustering was chosen in order to obtain clusters of patients on average well separated from the other clusters, emphasizing the homogeneity of their characteristics (QST features). For pain tests, correlations (Pearson's parametric and Spearman's nonparametric) between threshold values and VAS scores were analyzed for each identified cluster separately.

A 95\% level of statistical significance was used for all statistical analyses, performed using SPSS version 10 software.

\section{RESULTS}

During the 2-year observation period, 20 males and 10 females with the ALD/ABCD1-related phenotype were studied. Table 1 shows the patient demographics, the mutations observed, 


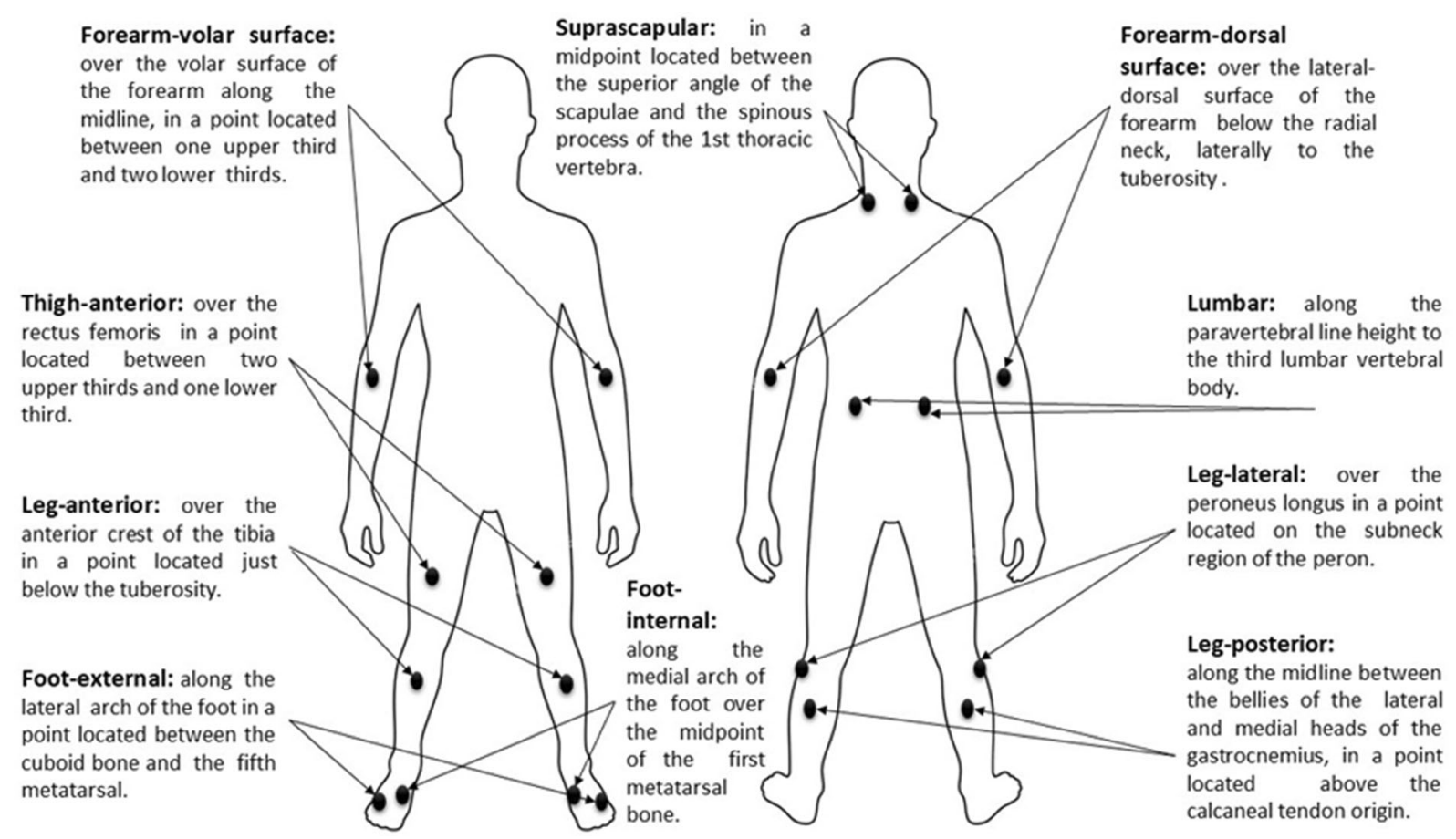

Fig. 1 Graphical representation of the 10 body points per side and anatomical landmarks description

VLCFA levels, the clinical phenotype, the presence of pain and the cluster in which patients were included for each sensory modality. Ten males were affected by adrenomyeloneuropathy $(\mathrm{AMN})$, one by cerebral adrenomyeloneuropathy (cAMN), one by cerebral adrenoleukodystrophy (CALD) and eight by Addison's disease only (AD). No specific diagnosis was made for the females.

The patients' mean age was 35.15 (range 10-64) years for males and 52.5 (range 22-68) years for females. AMN/CAMN were significantly older than $\mathrm{AD} \quad(44.8 \pm 14.0 \quad$ vs. $22.2 \pm 7.7 ; p<0.002)$. All males were symptomatic, whereas 8 of the 10 females were symptomatic, with varying degrees of myelopathy signs. While most of the males were under treatment (i.e. cortisone, glycerol trioleate/erucic acid and conjugate linoleic acid mixture, etc.), the females were all drug-free.

Subjects differed greatly in age, years since onset of the disease, clinical variant and degree of patient collaboration. In a few patients, the severity of the disorder did not allow completion of the testing procedure; thus, for some measurements there were missing values, accordingly different numbers of subjects entered the cluster analysis. The male data were analyzed based on the clinical form.

\section{Very Long Chain Fatty Acid (VLCFA)}

VLCFA determined in all subjects according to standard procedures [34] are reported in Table 2. One-way ANOVA applied to C24/C22 and C26/ C22 ratios revealed a significant effect of the factor Sex $(F(1,27)=11.79, \quad p<0.001$ and $F(1,27)=9.26, p<0.005$, respectively) due to the higher values present in males than in females. No differences were found in the ratios between male patients suffering from AMN/ cAMN/cALD $(n=12)$ and $\mathrm{AD}(n=8)$, although there was a strong tendency towards higher values in the former group (Table 2).

\section{Pain Features}

As reported in Table 1, pain was reported by 14/30 (46.7\%) patients: $6 / 20$ male (30\%, 1 AD, 5 AMN) and 8/10 female (80\%). In both sexes, pain would be defined as "classical" neuropathic 
pain in some cases, while in others it was due to various abnormal motor dysfunctions, as side effects of the disease. All pain indices (VAS, QUIDtot,s,a,e, Margolis) except QUIDm were slightly higher (i.e. worse) in females than in males (Table 3), but no significant differences were found. One AD subject (\#11, Table 1) recalled having felt minimal pain when he suffered a traumatic injury of the brachial plexus and during the postoperative period after surgical repair. Another patient (AMN, \#19, Table 1) reported burning pain in the legs where there were altered perfusion areas, edema and dystrophic changes of the tissue with ulcers.

\section{Quantitative Sensory Testing (QST)}

QST was carried out in all patients; in most cases, all 100 QST data (5 tests $\times 20$ body points) for the various tests were obtained for each patient. For these data, males and females were considered together because a preliminary statistical comparison, using the Mann-Whitney test, did not reveal significant differences.

\section{QST: Thermal Sensation}

All patients completed the test. The drop of acetone administered to the different points induced abnormal sensations in 13/20 males (65\%, 9 AMN, 1 cAMN, 1 cALD, 2 AD) and 6/10 females $(60 \%)$. In particular, eight males $(40 \%$, 6 AMN, 1 cAMN, 1 cALD) and four females $(40 \%)$ did not feel any sensation, one male $(\mathrm{AMN})$ and one female reported a mixture of sensations ranging from a faint perception to no perception, two males (AMN) mentioned a weak sensation, and two males (AD) and one female were unable to identify what they perceived. In addition, one male (AMN, \#5, Table 1) and one female experienced allodynia; in particular, the male subject reported burning pain in an area distant from the stimulated point. The sensory abnormalities were always in the lower extremities. The remaining $7 / 20$ males $(1 \mathrm{AMN}, 6 \mathrm{AD})$ and 4/10 females reported normal sensation at all points.

\section{QST: Light Tactile Sensation}

The tactile test was carried out in all subjects at each point. Light brushing of the points with cotton wool evoked an abnormal sensation in $7 / 20$ males (35\%, 5 AMN, 1 cAMN, 1 cALD). In particular, five subjects (4 AMN, 1 cAMN) did not detect the stimulus, one AMN had a very weak perception and one cALD felt mixed sensory abnormalities, i.e. no sensation at some points, an ambiguous sensation at others. Among those who did not perceive the stimulus, one subject (AMN \#5, Table 1) complained of burning pain in a distant area also after this kind of stimulation. The sensory abnormalities were always in the lower extremities. The remaining 13 males and all the females showed normal light tactile sensations.

\section{QST: von Frey Mechanical Detection Threshold (MDT)}

All patients underwent the test, although it was not completed in five males and two females. The size of the probe able to evoke the sensation varied greatly from one subject to another; for example, on the right foot external point, it

Table 2 Biochemical determinations in males and females

\begin{tabular}{lllll}
\hline & Males & & Females $(\boldsymbol{\mu m o l} / \mathbf{l})$ \\
\cline { 2 - 5 } & All males $(\boldsymbol{\mu m o l} / \mathbf{l})$ & AD $(\boldsymbol{\mu m o l} / \mathbf{l})$ & AMN/cAMN/cALD $(\boldsymbol{\mu m o l} / \mathbf{l})$ & \\
\hline VLCFA & $2.5 \pm 0.2$ & $2.0 \pm 0.5$ & $2.9 \pm 0.9$ & $2.19 \pm 0.29$ \\
C24/C22 & $1.5 \pm 0.1$ & $1.7 \pm 0.3$ & $1.6 \pm 0.4$ & $1.13 \pm 0.05^{* *}$ \\
C26/C22 & $0.07 \pm 0.01$ & $0.07 \pm 0.02$ & $0.08 \pm 0.03$ & $0.05 \pm 0.003^{* *}$ \\
\hline
\end{tabular}

C24/C22 and C26/C22 ratios were compared

${ }^{* *} p<0.01$ vs. other sex same ratio 
Table 3 Pain parameters

\begin{tabular}{|c|c|c|c|c|}
\hline Instruments & All & Males & Females & $p$ \\
\hline VAS & $5.9 \pm 2.4$ & $5.5 \pm 1.9$ & $6.1 \pm 2.9$ & ns \\
\hline QUID tot & $14.4 \pm 4.7$ & $14 \pm 6.3$ & $14.8 \pm 3.6$ & ns \\
\hline QUID sensory & $7.7 \pm 3.1$ & $7.0 \pm 3.0$ & $8.3 \pm 3.3$ & ns \\
\hline QUID affective & $1.7 \pm 1.3$ & $1.5 \pm 1.6$ & $1.9 \pm 1.1$ & ns \\
\hline QUID evaluative & $4.4 \pm 3.2$ & $4.3 \pm 3.8$ & $4.4 \pm 3.0$ & ns \\
\hline QUID miscellaneous & $0.6 \pm 1.1$ & $1.2 \pm 1.3$ & $0.3 \pm 0.7$ & ns \\
\hline QUID PPI & $1.0 \pm 0.9$ & $1.2 \pm 1.0$ & $0.9 \pm 1.0$ & ns \\
\hline Margolis \% & $21.3 \pm 15.0$ & $19.7 \pm 11.9$ & $22.5 \pm 17.7$ & ns \\
\hline
\end{tabular}

Intensity (VAS), quality (QUID) and extent (Margolis) of pain in males and females. ANOVA was carried out between male and female groups. Differences were considered significant with $p<0.05$

ns not significant

ranged from 2.44 to 5.88 in males and 2.44 to 5.56 in females. Male subjects suffering from AMN/CAMN/CALD always showed a higher threshold than the $\mathrm{AD}$, and the difference was significant at 10 points (Table 4 ).

The MDT measurements recorded in all males and females were used in a cluster analysis, which allowed the identification of four homogeneous groups of patients with distinct, well-interpretable threshold profiles (see values from one representative point in Fig. 2 and median values for each cluster in S1 Table). The first cluster had six patients, three male (all $\mathrm{AMN}$ ) and three female. MDT values greatly increased from the trunk to the feet, and were extremely high in the lower limbs, indicating strong hyposensitivity to this type of stimulus. The second cluster had three males ( $2 \mathrm{AMN}, 1$ $\mathrm{AD})$ and one female; in these subjects the MDT values at the foot external points were extremely low, indicating hypersensitivity to the punctiform tactile stimulus. The third cluster had five subjects, four male ( $3 \mathrm{AD}$ and $1 \mathrm{AMN}$ ) and one female. In this group the mechanical threshold recorded on the left and right side coincided until the knee. Below the knee, the values of the ipsilateral and contralateral points differed, although for each side the values at all three points were very similar. The fourth cluster had six subjects, four male (2 AMN, 1
cAMN, 1 AD) and two female. The MDT values of the left and right side were the same, except for those at the forearm dorsal surface, leg posterior and foot external points; for the last point, the value on the left side was very low, suggesting high sensitivity to the stimulus.

There were no significant differences among clusters based on age, type of mutation or blood VLCFA amount.

Table 5 reports the distribution within each cluster of the patients with abnormal sensations evoked by thermal and light tactile stimuli. Moreover, the table includes the number of patients with chronic pain belonging to each cluster.

\section{QST: von Frey Mechanical Pain Threshold} (MPT) All patients underwent the test, although it was not completed in five males and two females. Twenty-five subjects (16 male, 9 female) reported pain when the von Frey filaments (size 6.10-6.65) were applied to the tested points; out of these, seven males (5 AMN, $1 \mathrm{cAMN}, 1 \mathrm{AD}$ ) and two females did not report pain at some points, and four males ( $1 \mathrm{AMN}, 3$ AD [\#20, 21, 22, Table 1]) and one female did not report pain at any point. In patients in which pain was reported, its intensity was usually low (VAS 1-3), being high (VAS 7-8) in only a few cases. 
Table 4 QST: von Frey mechanical detection threshold (MDT) in males

\begin{tabular}{llcc}
\hline Point & AD & AMN/cAMN/cALD & $p<$ \\
\hline lumb-R & $3.29 \pm 3.3$ & $33.8 \pm 42.2$ & 0.05 \\
leg-lat-R & $3.35 \pm 3.1$ & $154.0 \pm 248$ & 0.02 \\
leg-lat-L & $4.2 \pm 2.8$ & $96.4 \pm 187.5$ & 0.01 \\
leg-ant-R & $3.3 \pm 3.0$ & $60.3 \pm 80.7$ & 0.02 \\
leg-ant-L & $3.6 \pm 3.0$ & $52.8 \pm 75.1$ & 0.01 \\
leg-post-R & $2.9 \pm 2.1$ & $89.0 \pm 172.3$ & 0.02 \\
leg-post-L & $4.3 \pm 2.6$ & $96.2 \pm 179.6$ & 0.02 \\
f-ext-L & $2.3 \pm 2.1$ & $49.9 \pm 81.9$ & 0.02 \\
f-int-R & $2.4 \pm 2.0$ & $90.3 \pm 181.4$ & 0.03 \\
f-int-L & $2.1 \pm 1.9$ & $45.1 \pm 81.4$ & 0.01 \\
\hline
\end{tabular}

Values at the 10 points where the difference between $\mathrm{AD}$ and AMN/cAMN/cALD male patients was significant (ANOVA, $p<0.05$ ). Points: leg, anterior (leg-ant); lumbar (lumb); leg, lateral (leg-lat); leg, posterior (leg-post); foot, external (f-ext); foot, internal (f-int)

$L$ left, $R$ right
The cluster analysis of MPT values and the corresponding VAS scores revealed two homogeneous clusters of patients with distinct characteristics (median, 2S Table): the first cluster included eight males (4 AD [\#1, 20, 21, 22, Table 1], 3 AMN, 1 cAMN), while the second cluster had eight males (4 AD, 4 AMN) and three females. At all points, MPT values were higher in cluster 1 than in cluster 2 , whereas the VAS scores were lower in cluster 1 than in cluster 2 .

Table 6 shows the distribution of the patients with abnormal sensations evoked by thermal and tactile stimuli within the two clusters obtained with MPT/VAS; the table also includes the number of patients suffering chronic pain. There were no significant differences among clusters based on age, type of mutation or blood VLCFA amount.

QST: Algometer Pressure Pain Threshold (PPT) Twenty-eight patients (20 male and 8 female) underwent the test, although it was not completed in five males. Twenty-six of them presented a PPT, while in nine males (5 AMN, 4

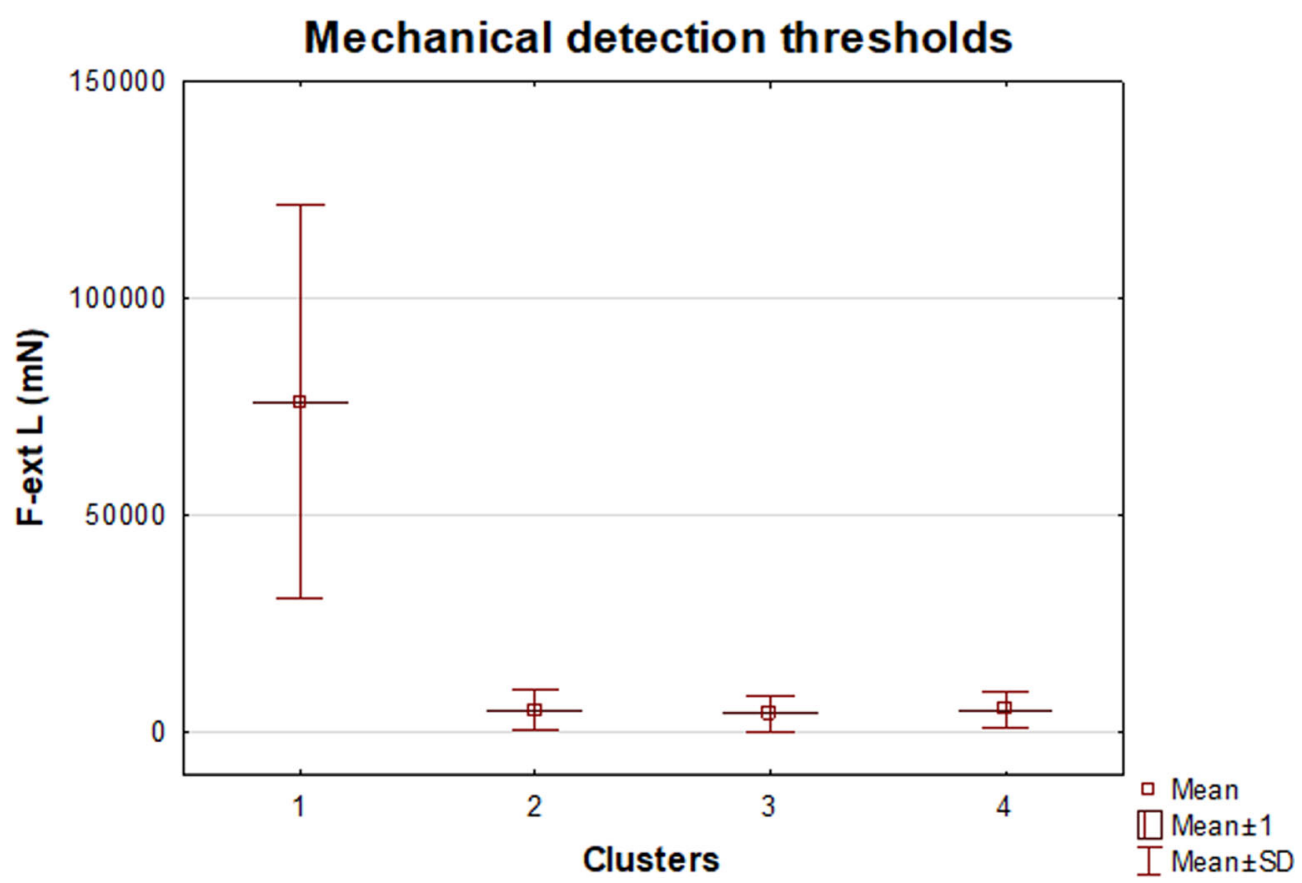

Fig. 2 QST: mechanical detection threshold (MDT). Mean MDT values at one representative point (foot, external left, f-ext L) in all clusters 
AD) and six females pain was evoked at all points, and in nine males (5 AMN, 1 cAMN, 2 $\mathrm{AD}$ and 1 cALD) and two females pain was evoked only at some points. The other two males (AD [\#21, 22], Table 1) did not report pain at any point at the maximum level of pressure administered $(5 \mathrm{~kg})$. Pain intensity (VAS) ranged mainly from 1 to 3 , being high (VAS 7-8) only in a few instances.

Cluster analysis of the PPT values and the corresponding VAS scores revealed two distinct groups of patients: the first cluster included five males ( $3 \mathrm{AMN}, 2 \mathrm{AD}$ ) and six females, and the second cluster had 11 males (6 AMN, 1 cAMN, 4 AD). At all points, the PPT values (median, 3S Table) were lower in cluster 1 than in cluster 2, while the VAS scores were higher in cluster 1 than in cluster 2 . A trend towards a negative correlation between PPT values and VAS scores was observed at 10 points in cluster 1 , reaching significance at one point (Table 7). By contrast, a positive correlation between the PPT values and VAS scores was found at 8 points in cluster 2, the correlation being significant at five of these points (Table 7).
Table 8 reports the distribution of the patients with abnormal sensations evoked by thermal and tactile stimuli within each cluster obtained with PPT/VAS values. The table also includes the number of patients with chronic pain. There were no differences between the clusters based on age, type of mutation or biochemical data.

\section{QST: Wind-Up Test}

All patients underwent and completed the test. Sixteen patients, 13 male $(8 \mathrm{AD}, 4 \mathrm{AMN}, 1$ cAMN) and 3 female, exhibited the wind-up phenomenon, i.e. an increase in the VAS score after repetition of the suprathreshold stimulus at the established point, the increase ranging from 1 to 6 .

\section{DISCUSSION}

Chronic pain and sensory features were analyzed in a cohort of male and female subjects with an $A B C D 1$-related phenotype. Almost half of these subjects reported chronic pain, with female subjects representing by far the higher

Table 5 Cluster features for mechanical detection threshold (MDT)

\begin{tabular}{llllcc}
\hline $\begin{array}{l}\text { Cluster } \\
\text { von Frey MDT } \\
\text { Cluster 1 vs. cluster 2 }\end{array}$ & $\begin{array}{l}\text { Males/ } \\
\text { females }\end{array}$ & Thermal & Light touch & Pain \\
\hline 1 & Higher threshold & Males & $2 / 3$ no sensation & $2 / 3$ no & $1 / 3$ \\
& (HYPOSENSITIVE) & Females & $2 / 3$ no sensation & sensation & $3 / 3$ \\
& & & & $0 / 3$ alterations \\
2 & Lower threshold & Males & $1 / 3$ no sensation & $1 / 3$ no & $2 / 3$ \\
& (HYPERSENSITIVE) & Females & $1 / 3$ alterations & sensation & $0 / 1$ \\
& & & $0 / 1$ alterations & $0 / 1$ alterations \\
3 & & Males & $2 / 4$ alterations & $0 / 4$ alterations & $1 / 4$ \\
& & Females & $1 / 1$ no sensation & $0 / 1$ alterations & $1 / 1$ \\
4 & & Males & $2 / 4$ no sensation $2 / 4$ light & $2 / 4$ no & $0 / 4$ \\
& & Females & sensation & sensation & $2 / 2$ \\
& & & $2 / 2$ no sensation & $0 / 2$ alterations & \\
\hline
\end{tabular}

Characteristics of the patients' sensory profiles in each cluster. Data are reported as frequency/total number of patients in the cluster. No sensation: the patient did not report any perception; Alterations: the patient reported an abnormal response 
Table 6 Cluster features for mechanical pain threshold (MPT)

\begin{tabular}{llllll}
\hline Cluster & $\begin{array}{l}\text { von Frey MPT } \\
\text { Cluster 1 vs. cluster 2 }\end{array}$ & $\begin{array}{l}\text { Males/ } \\
\text { females }\end{array}$ & Thermal & Light touch & Pain \\
\hline 1 & Higher threshold & Males & $2 / 8$ no sensation & $3 / 8$ no sensation & $2 / 8$ \\
& Lower VAS (HYPOALGESIC) & Females & $\begin{array}{c}2 / 8 \text { light } \\
\text { sensation }\end{array}$ & & \\
& & & & \\
2 & Lower threshold & Males & $4 / 8$ no sensation & $1 / 8$ no sensation $1 / 8$ light & $3 / 8$ \\
& Higher VAS & Females & $1 / 3$ no sensation & sensation & $2 / 3$ \\
& & & $0 / 3$ no sensation & \\
\hline
\end{tabular}

Characteristics of the patients' sensory profile in each cluster. No females were present in cluster 1

percentage. Male patients differed greatly in the sensory phenotype according to the clinical variants of the disease, i.e. adrenomyeloneuropathy $(\mathrm{AMN})$, cerebral AMN (cAMN), cerebral adrenoleukodystrophy (cALD) and Addison's disease only (AD). We found significant sex differences in most of the applied tests.

$\mathrm{X}$-ALD is characterized by the accumulation of VLCFA which appears to trigger the pathological events $[1,2,10]$. In the neural forms, the increased amount of VLCFA was shown to modify the structure and functions of the lipidic component of axons [17, 35]. The AMN axonopathy mainly involves large myelinated fibers (forming the major motor and mechanical sensory pathways), but small myelinated fibers (forming nociceptive and thermal sensory

Table 7 PPT/VAS correlations per cluster

\begin{tabular}{llllll}
\hline Points & \multicolumn{2}{l}{ Cluster $\mathbf{1}$} & & & \multicolumn{2}{c}{ Cluster 2 } \\
\cline { 2 - 3 } \cline { 6 - 6 } & $\boldsymbol{r}$ & $\boldsymbol{p}$ & & $\boldsymbol{r}$ & $\boldsymbol{p}$ \\
\hline fa-vs-R & -0.378 & $\mathrm{~N} s$ & & +0.639 & $<0.05$ \\
fa-vs-L & -0.540 & $\mathrm{~N} s$ & & +0.762 & $<0.01$ \\
fa-ds-R & -0.770 & $<0.05$ & +0.830 & $<0.01$ \\
fa-ds-L & -0.623 & $\mathrm{~N} s$ & & +0.745 & $<0.01$ \\
f-ext-R & -0.619 & $\mathrm{Ns}$ & & +0.647 & $<0.01$ \\
\hline
\end{tabular}

Correlations between PPT values and VAS scores within each cluster. Points: forearm, volar surface (fa-vs); forearm, dorsal surface (fa-ds); foot, external (f-ext)

$L$ left, $R$ right pathways) have recently been found to be involved $[15,17]$. Thus, both large and small $A \delta$ myelinated fibers may be damaged contemporaneously, with complex sensory outcomes. In the cerebral forms, severe demyelinization of the white matter, neuron shrinkage in the grey matter aggregates and fibrillary gliosis have been observed. These conditions result in dysfunction of brain tracts, nuclei and structures up to irreversible failure $[36,37]$. In the $\mathrm{AD}$ clinical form, only adrenal cortex cells are affected, with loss of their functions $[7,8]$.

Studies have reported altered sensation and chronic pain in subjects affected by ALD; pain was localized mainly in the lower limbs $[17,38,39]$ or was diffuse [8]. In the present study, pain was observed in a high percentage of patients (nearly 50\%), with a significant prevalence of females; males with pain were mainly affected by AMN. No sex differences were found in pain intensity, quality or extension. In particular, some patients suffered from a pure form of neuropathic pain, while others showed a musculoskeletal component, in some instances due to the coexistent impairment of $A \beta$ motor fibers, in others caused by conditioned behavioral responses. Of note, although avulsion of the brachial plexus usually causes unbearable pain [40], one $\mathrm{AD}$ patient mentioned low-intensity pain during the traumatic injury of the brachial plexus and the postoperative period. Another patient presented areas of altered perfusion, edema and trophic changes of skin and subcutaneous tissues in the legs, all signs 
Table 8 Cluster features for pressure pain threshold (PPT)

\begin{tabular}{llllll}
\hline Cluster & $\begin{array}{l}\text { Algometer PPT } \\
\text { Cluster 1 vs. cluster 2 }\end{array}$ & Males/females & Thermal & Light touch & Pain \\
\hline 1 & Lower threshold & Males & $2 / 5$ no sensation & $1 / 5$ no sensation & $2 / 5$ \\
& Higher VAS (HYPERALGESIC) & Females & $4 / 6$ no sensation & $0 / 6$ no sensation & $5 / 6$ \\
2 & Higher Threshold & Males & $8 / 11$ no sensation & $4 / 11$ no sensation & $3 / 11$ \\
& Lower VAS (HYPOALGESIC) & Females & & & \\
\hline
\end{tabular}

Characteristics of the patients' sensory profile in each cluster. No females were present in cluster 2

presumably dependent on an abnormal sympathetic nervous system regulation of blood flow. In this case, primary impairment of the myelinic part of the sympathetic system $[15,17]$ and functional coupling between lesioned peripheral afferent nerve and sympathetic fibers [41], both generating or worsening pain, can be hypothesized. There are few literature reports focusing on the impairment of nociceptive pathways in this disease [15-17]. In AMN, the pain pathways may undergo degeneration in both the central and peripheral neural systems, and thus fibers may lose the ability to transmit signals or may fire spontaneously or inappropriately [42]. Kumar [16] described lesions of the spinothalamic tract localized in the thalamus in an AMN patient, while Horn [15] and Yague [17] highlighted small fiber dysfunctions.

A persistent injury or disease affecting the neural system can produce enhanced synaptic strength due to neuronal [43] and glial cell upregulation [44]; moreover, the latter component may be enhanced when there is a concurrent condition of neuroinflammation [45-48]. Interestingly, while in the cerebral clinical form (cAMN/cALD) of X-ALD a huge quantity of monocytes/macrophages and T-lymphocytes were found to cross the blood-brain barrier, inducing the microglia cells to undergo aberrant activation [49], in the AMN clinical variant, neuroinflammation appears to be absent or mild, although monocyte and macrophage infiltration and activation of microglia cells [50] have been found. Moreover, Marchetti et al. [51] showed increased blood levels of some inflammatory cytokines (IL-1, IL8 ) in asymptomatic ALD subjects and of TNF- $\alpha$ in AMN patients, suggesting a neuro-inflammatory condition in AMN subjects as well. These immune cells secrete large amounts of proinflammatory cytokines, chemokines and also iNOS and other inflammatory mediators [52] which, increasing NMDA release at the synapse [44], amplify the nociceptive signaling, a condition that helps to explain the high percentage of patients suffering pain in this clinical form.

The functional status of small A $\delta$ and large $\mathrm{A} \beta$ fibers was investigated by means of quantitative sensory testing (QST) $[19,21]$. Standardized tests that activate specific fibers and switch on particular sensory submodalities were administered to investigate the ongoing behavior of the somatosensory system.

The functioning of A $\delta$ fibers was examined by measuring the mechanical pain thresholds (von Frey and algometer tests). Interestingly, despite the presence of chronic pain in most of the patients, several males and females did not report pain at some/any points. This important condition of hypo/insensitivity can be attributed in AMN/CAMN/CALD patients to axon degeneration and thus a loss of function; in the $\mathrm{AD}$ patients, in which the integrity of the neural system has been largely confirmed [8, 9], an involvement of $B$-endorphins can be hypothesized, as they have been found in peroxisomes of cells positive to the adrenoleukodystrophy protein (ALDP) [53, 54].

The response to the repeated stimulation by suprathreshold painful stimuli (wind-up) appears to confirm this interpretation. Indeed, all the $\mathrm{AD}$ subjects displayed this phenomenon, i.e. an increase in pain intensity in the 
stimulated area, while only a few AMN patients reported a heightened sensation. It is reasonable to infer that, in the AMN patients, degeneration or atrophy of the fibers was too severe to allow a gain of the signal, while in those who presented wind-up, the surviving nociceptors and axons were sufficient to contribute to a potentiated synaptic transmission [55]; alternatively, in these subjects the signal was likely maintained by vicarious mechanisms such as ectopic impulses which preserved the connection with the sensing brain [56]. It is worth noting that AD patients developed enhanced pain, although their nociceptive pathways were hyposensitive; thus, repeated stimulations as produced in the wind-up test allowed their activation and also their increased excitability.

The functional status of A $\delta$ fibers was further assessed by means of the thermal test. A multifaceted spectrum of responses was observed, indicating that the degree of sensory loss varied greatly among subjects/clinical variants. Several males and females manifested no sensation or reported a minimal or ambiguous perception, particularly in the lower extremities, corroborating the dying-back pattern of the axonopathy. All males except two suffered from the neural clinical variant of the disorder; one of them and also a female exhibited allodynia in a remote area, showing the occurrence of central sensitization. These findings are in agreement with Yague et al. [17], showing thermoalgesic hypoesthesia in the lower body district of AMN subjects, and Horn et al. [15], who observed altered thermal sensitivity in the lower limbs of AMN males and females.

The performance of large $A \beta$ fibers was examined by means of the mechanical threshold test. The thresholds were higher in the patients diagnosed with the neural variant than in $\mathrm{AD}$ patients, the difference being significant in the lower body district. Cluster analysis aggregated patients into four groups with distinct profiles with respect to the function examined. These outcomes substantiate a distal proximal pattern of the axonal degeneration in $\mathrm{A} \beta$ fibers as well. Moreover, a high percentage of AMN subjects and both patients diagnosed with the cerebral form did not perceive the light tactile stimulus or reported an unclear or weak sensation. As in the thermal test, one AMN subject experienced a burning pain in a distant area. All these aberrant responses were distributed in the lower limbs, confirming the length-dependent pattern of the axonopathy. Of note, no $\mathrm{AD}$ subject or female reported an altered sensation, even when the testing was carried out in areas presenting anomalies in other sensory submodalities. Thus, large $A \beta$ fibers were impaired in several patients affected by the neural variant of the disorder, but their functioning was preserved in females and $\mathrm{AD}$ subjects.

\section{Study Limitations}

Some limitations of the study must be mentioned. The sample was too small to give unambiguous and conclusive findings, even though the patients were randomly enrolled over 2 years in the two major Italian study centers. Moreover, the QST findings must be regarded as closely linked to the contingencies; indeed, many potential confounding factors can influence sensory testing [57-60]. Lastly, this is a progressive disease, and thus the assessment describes the features only at the time of testing. Studies on a larger number of patients are needed to confirm our results.

\section{CONCLUSIONS}

To our knowledge, this is the first time that a systematic pain study has been carried out in patients suffering from this neuro-metabolic syndrome. We applied an objective method, the QST, to measure the sensory phenotype of our subjects who, unlike in similar studies of neuropathic patients, were tested at numerous points to obtain a body distribution of the alterations, confirming that the disease has a bottom-up pattern. Given that the sensory profile is a surrogate of the mechanisms underlying individual neuropathic pain [61], the outcomes of our study represent a premise for proposing targeted therapies, in agreement with international guidelines and, where possible, with an etiological approach. 


\section{ACKNOWLEDGEMENTS}

We thank the participants in the study, the University of Siena, Bambino Gesù Children's Hospital (Rome, Italy) and IRCCS C. Besta Neurological Institute Foundation (Milan, Italy) for the human resources provided for the present study and Dr. Peter Christie for the English revision of the text.

Funding. No funding or sponsorship was received for this study or for publication of this article.

Authorship. All named authors meet the International Committee of Medical Journal Editors (ICMJE) criteria for authorship for this article, take responsibility for the integrity of the work as a whole, and have given their approval for this version to be published.

Disclosures. All Authors, Valeria Bachiocco, Marco Cappa, Anna Petroni, Ettore Salsano, Carla Bizzarri, Ilaria Ceccarelli, Gabriele Cevenini, Viviana Pensato and Anna Maria Aloisi, declare no conflict of interest.

Compliance with Ethics Guidelines. The study adhered to the Declaration of Helsinki and was approved by the local ethics committees of the Bambino Gesù Children's Hospital and the Neurological Institute C. Besta; all the patients and their parents or guardians gave their written informed consent to use their clinical data in anonymized form (Mod.CUP_02consinf_15/07/2003 and subsequent amendments).

Data Availability. The datasets generated and/or analyzed during the current study are available from the corresponding author upon reasonable request.

Open Access. This article is licensed under a Creative Commons Attribution-NonCommercial 4.0 International License, which permits any non-commercial use, sharing, adaptation, distribution and reproduction in any medium or format, as long as you give appropriate credit to the original author(s) and the source, provide a link to the Creative Commons licence, and indicate if changes were made. The images or other third party material in this article are included in the article's Creative Commons licence, unless indicated otherwise in a credit line to the material. If material is not included in the article's Creative Commons licence and your intended use is not permitted by statutory regulation or exceeds the permitted use, you will need to obtain permission directly from the copyright holder. To view a copy of this licence, visit http://creativecommons.org/licenses/by$\mathrm{nc} / 4.0 /$.

\section{REFERENCES}

1. Cappa M, Bizzarri C, Vollono C, Petroni A, Banni S. Adrenoleukodystrophy. In: Ghizzoni L, Cappa M, Chrousos G, Loche S, Maghnie M, editors. Pediatric adrenal diseases. Endocr. dev., vol. 20. Basel: Karger; 2011. p. 149-60.

2. Berger J, Gärtner J. X-linked adrenoleukodystrophy: clinical, biochemical and pathogenetic aspects. Biochim Biophys Acta. 2006;1763:1721-32.

3. Cappa M, Cambiaso P, Del Balzo P, Benedetti S, Borrelli P. Hormonal evaluation in adrenoleukodystrophy. In: Uziel G, Wandres RJA, Cappa M, editors. Adrenoleukodystrophy and other peroxisomal disorders. Clinical, biochemical, genetic and therapeutic aspects. Amsterdam: Excerpta Medica; 1990. p. 81-92.

4. Petroni A, Paroni R, Aloisi AM, Blasevich M, Haman $\mathrm{N}$, Fessas D. Thermogenic flux induced by lignoceric acid in peroxisomes isolated from HepG2 cells and from $\mathrm{X}$-adrenoleukodystrophy and control fibroblasts. J Cell Physiol. 2019;234:1-5.

5. Ruiz M, Jové M, Schlüter A, Casasnovas C, Villarroya F, Guilera C, Ortega FJ, Naudí A, Pamplona R, Gimeno R, Fourcade S, Portero-Otìn M, Pujol A. Altered glycolipid and glycerophospholipid signaling drive inflammatory cascades in adrenomyeloneuropathy. Hum Mol Gen. 2015;24: 6861-76.

6. Schlüter A, Espinosa L, Fourcade S, Galino J, López E, Ilieva E, Morató L, Asheuer M, Cook T, McLaren A, Reid J, Kelly F, Bates S, Aubourg P, Galea E, Pujol A. Functional genomic analysis unravels a metabolic-inflammatory interplay in adrenoleukodystrophy. Hum Mol Gen. 2012;21:1062-77. 
7. Schlüter A, Sandoval J, Fourcade S, Díaz-Lagares A, Ruiz M, Casaccia P, Esteller M, Pujol A. Epigenomic signature of adrenoleukodystrophy predicts compromised oligodendrocyte differentiation. Brain Pathol. 2018;28:902-19.

8. Berger J, Forss-Petter S, Eichler FS. Pathophysiology of X-linked adrenoleukodystrophy. Biochimie. 2014;98:135-42.

9. Singh J, Khan M, Singh I. Silencing of Abcd1 and Abcd2 genes sensitizes astrocytes for inflammation: implication for X-adrenoleukodystrophy. J Lipid Res. 2009;50:135-47.

10. Singh I, Pujol A. Pathomechanisms underlying X-adrenoleukodystrophy: a three-hit hypothesis. Brain Pathol. 2010;20:838-44.

11. Weber FD, Wiesinger C, Forss-Petter S, Regelsberger G, Einwich A, Weber WH, Köhler W, Stockinger H, Berger J. X-linked adrenoleukodystrophy: very long-chain fatty acid metabolism is severely impaired in monocytes but not in lymphocytes. Hum Mol Gen. 2014;23:2542-50.

12. Engelen M, Barbier M, Dijkstra IM, Schür R, de Bie RM, Verhamme C, Dijkgraaf MG, Aubourg PA, Wanders RJ, van Geel BM, de Visser M, Poll-The BT, Kemp S. X-linked adrenoleukodystrophy in women: a cross-sectional cohort study. Brain. 2014;137:693-706.

13. Engelen M, Kemp S, Poll-The BT. X-linked adrenoleukodystrophy in women: pathogenesis and treatment. Curr Neurol Neurosci Rep. 2014;14: 486.

14. Schirinzi T, Vasco G, Aiello C, Rizzo C, Sancesario A, Romano A, Favetta M, Petrarca M, Paone L, Castelli E, Bertini ES, Cappa M. Natural history of a cohort of ABCD1 variant female carriers. Eur J Neurol. 2019;26:326-32.

15. Horn MA, Nilsen KB, Jørum E, Mellgren SI, Tallaksen CME. Small nerve fiber involvement is frequent in X-linked adrenoleukodystrophy. Neurology. 2014;82:1678-83.

16. Kumar AJ, Köhler W, Kruse B, Naidu S, Bergin A, Edwin D, Moser HW. MR findings in adult-onset adrenoleukodystrophy. Am J Neuroradiol. 1995;16: 1227-37.

17. Yagüe S, Veciana M, Casasnovas C, Ruiz M, Pedro J, Valls-Solé J, Pujol A. Evaluation of afferent pain pathways in adrenomyeloneuropathic patients. Clin Neurophysiol. 2018;129:507-15.

18. Jensen TS, Baron R, Haanpää M, Kalso E, Loeser JD, Rice AS, Treede RD. A new definition of neuropathic pain. Pain. 2011;152:2204-5.
19. Rolke R, Baron R, Maier C, Tölle TR, Treede R-D, Beyer A, Binder A, Birbaumer N, Birklein F, Bötefür IC, Braune S, Flor $\mathrm{H}$, Huge V, Klug R, Landwehrmeyer GB, Magerl W, Maihöfner C, Rolko C, Schaub C, Scherens A, Sprenger T, Valet M, Wasserka B. Quantitative sensory testing in the German Research Network on Neuropathic Pain (DFNS): standardized protocol and reference values. Pain. 2006;123:231-43.

20. Rolke R, Magerl W, Campbell KA, Schalber C, Caspari S, Birklein F, Treede R-D. Quantitative sensory testing: a comprehensive protocol for clinical trials. Eur J Pain. 2006;10:77-88.

21. Backonja MM, Attal N, Baron R, Bouhassira D, Drangholt M, Dyck PJ, Edwards RR, Freeman R, Gracely R, Haanpaa MH, Hansson P, Hatem SM, Krumova EK, Jensen TS, Maier C, Mick G, Rice AS, Rolke R, Treede R-D, Serra J, Toelle T, Tugnoli V, Walk D, Wallace MS, Ware M, Yarnitsky D, Ziegler D. Value of quantitative sensory testing in neurological and pain disorders: NeuPSIG consensus. Pain. 2013;154:1807-19.

22. Freeman R, Baron R, Bouhassira D, Cabrera J, Emir B. Sensory profiles of patients with neuropathic pain based on the neuropathic pain symptoms and signs. Pain. 2014;155:367-76.

23. Maier C, Baron R, Tölle TR, Binder A, Birbaumer N, Birklein F, Gierthmühlen J, Flor H, Geber C, Huge V, Krumova EK, Landwehrmeyer GB, Magerl W, Maihöfner C, Richter H, Rolke R, Scherens A, Schwarz A, Sommer C, Tronnier V, Üçeyler N, Valet M, Wasner G, Treede RD. Quantitative sensory testing in the German Research Network on Neuropathic Pain (DFNS): somatosensory abnormalities in 1236 patients with different neuropathic pain syndromes. Pain. 2010;150:439-50.

24. Rabey M, Slater H, O'Sullivan P, Beales D, Smith A. Somatosensory nociceptive characteristics differentiate subgroups in people with chronic low back pain: a cluster analysis. Pain. 2015;156:1874-84.

25. Kohler W, Sokolowski P. A new disease-specific scoring system for adult phenotypes of X-linked adrenoleukodystrophy. J Mol Neurosci. 1999;13: 247-52.

26. Engelen $M$, Kemp S, de Visser $M$, et al. X-linked adrenoleukodystrophy (X-ALD): clinical presentation and guidelines for diagnosis, follow-up and management. Orphanet J Rare Dis. 2012;7:51.

27. Laureti S, Falorni A, Volpato M, Casucci G, Picchio ML, Angeletti G, Luthman H, Brunetti P, Betterle C, Santeusanio F. Absence of circulating adrenal autoantibodies in adult-onset X-linked adrenoleukodystrophy. Horm Metab Res. 1996;28: 319. 
28. De Benedittis G, Massei R, Nobili R, Pieri A. The Italian Pain Questionnaire. Pain. 1988;33:53-62.

29. Margolis RB, Tait RC, Krause SJ. A rating system for use with patient pain drawings. Pain. 1986;24: 57-65.

30. Vissers K, Meert T. A behavioral and pharmacological validation of the acetone spray test in gerbils with a chronic constriction injury. Anesth Analg. 2005;101:457-64.

31. Gierthmühlen J, Maier C, Baron R, Tölle T, Treede RD, Birbaumer N, Huge V, Koroschetz J, Krumova EK, Lauchart M, Maihöfner C, Richter H, Westerman A, German Research Network on Neuropathic Pain (DFNS) Study Group. Sensory signs in complex regional pain syndrome and peripheral nerve injury. Pain. 2012;153:765-74.

32. Vase L, Nikolajesen L, Christensen B, Egsgaard LL, Arendt-Nielsen L, Svensson P, Jensen TS. Cognitiveemotional sensitization contributes to wind-up-like pain in phantom limb pain patients. Pain. 2011;152:157-62.

33. Melzack R, Stillwell DM, Fox EJ. Trigger points and acupuncture points for pain: correlations and implications. Pain. 1977;3:3-23.

34. Cappa M, Bizzarri C, Petroni A, Carta G, Cordeddu L, Valeriani M, Vollono C, De Pasquale L, Blasevich M, Banni S. A mixture of oleic, erucic and conjugated linoleic acids modulates cerebrospinal fluid inflammatory markers and improves somatosensorial evoked potential in X-linked adrenoleukodystrophy female carriers. J Inherit Metab Dis. 2012;35: 899-907.

35. Powers JM. The pathology of peroxisomal disorders with pathogenetic considerations. J Neuropathol Exp Neurol. 1995;54:710-9.

36. Benzoni C, Farina L, Pensato V, Marotta G, Kuqo A, Mauro E, Pareyson D, Salsano E. Leukoencephalopathy with predominant infratentorial involvement caused by a novel ABCD1 mutation: does the spinocerebellar variant of adrenoleukodystrophy exist? Neurologist. 2019;24: 194-7.

37. Ochi K, Noda K, Kawakami H, Oka M, Imon $\mathrm{Y}$, Mimori Y, Nakamura S. Dentato-rubral tract involvement in adult-onset adrenoleukodystrophy. Am J Neuroradiol. 1988;19:1904.

38. Foschi M, Vacchiano V, Avoni P, Incensi A, Battaglia S, Donadio V, Panzeri E, Bassi MT, Liguori R, Rizzo G. Broadening the spectrum of adulthood X-linked adrenoleukodystrophy: a report of two atypical cases. Front Neurol. 2019;10:70.
39. Jack GH, Malm-Willadsen K, Frederiksen A, Glintborg D, Andersen M. Clinical manifest X-linked recessive adrenoleukodystrophy in a female. Case Rep Neurol Med. 2013;2013:491730.

40. Lovaglio AC, Socolovsky M, Di Masi G, Bonilla G. Treatment of neuropathic pain after peripheral nerve and brachial plexus traumatic injury. Neurol India. 2019;67(Supplement):S32-7.

41. Jänig $\mathrm{W}$, Baron $\mathrm{R}$. The role of the sympathetic nervous system in neuropathic pain: clinical observations and animal models. In: Hansson PT, Fields HL, Hill RG, Marchettini P, editors. Neuropathic pain: pathophysiology and treatment. Progress in pain research and management, vol. 21. Seattle: IASP Press; 2001. p. 107-24.

42. Black JA, Dib-Hajj S, Cummins T, Okuse K, Baker M, Wood JN, Waxman SG. Sodium channels as therapeutic targets in neuropathic pain. In: Hansson PT, Fields HL, Hill RG, Marchettini P, editors. Neuropathic pain: pathophysiology and treatment. Progress in pain research and management, vol. 21. Seattle: IASP Press; 2001. p. 19-36.

43. Woolf CJ. Central sensitization: implications for the diagnosis and treatment of pain. Pain. 2011;152(3 Suppl):S2-15.

44. Ji R-R, Berta T, Nedergaard M. Glia and pain: is chronic pain a gliopathy? Pain. 2013;154(Supplement 1):S10-28.

45. de Goeij M, van Eijk LT, Vanelderen P, Wider-Smith $\mathrm{OH}$, Vissers KC, van der Hoeven JG, Kox M, Scheffer GJ, Pickkers P. Systemic inflammation decreases pain threshold in humans in vivo. PLoS ONE. 2013;8:e84159.

46. Kawasaki Y, Zhang L, Cheng J-K, Ji R-R. Cytokine mechanisms of central sensitization: distinct and overlapping role of interleukin- $1 \beta$, interleukin- 6 and tumor necrosis factor- $\alpha$ in regulating synaptic and neuronal activity in the superficial spinal cord. J Neurosci. 2008;28:5189-94.

47. Lyman M, Lloyd DG, Ji X, Vizcaychipi MP, Ma D. Neuro-inflammation: the role and the consequences. Neurosci Res. 2014;79:1-12.

48. Zhang XC, Kainz V, Burstein R, Levy D. Tumor necrosis factor- $\alpha$ induces sensitization of meningeal nociceptors mediated via local COX and p38 MAO kinase actions. Pain. 2011;152:140-9.

49. Weinhofer I, Zierfuss B, Hametner S, Wagner M, Popitsch N, Machacek C, Bartolini B, Zlabinger G, Ohradanova-Repic A, Stockinger $\mathrm{H}$, Köhler W, Höftberger R, Regelsberger G, Forss-Petter S, Lassmann $\mathrm{H}$, Berger J. Impaired plasticity of 
macrophages in X-linked adrenoleukodystrophy. Brain. 2018;141:2329-42.

50. Gong Y, Sasidharan N, Laheji F, Frosch M, Musolino P, Tanzi R, Kim DY, Biffi A, El Khoury J, Eichler F. Microglial dysfunction as a key pathological change in adrenomyeloneuropathy. Ann Neurol. 2017;82: 813-27.

51. Marchetti DP, Donida B, Jacques CE, Deon M, Hauschild TC, Koehler-Santos P, de Moura CD, Coitinho AS, Jardim LB, Vargas CR. Inflammatory profile in X-linked adrenoleukodystrophy patients: understanding disease progression. J Cell Biochem. 2018;119:1223-33.

52. Abbas AK, Lichtman AH. Cellular and Molecular Immunology. Philadelphia: WA Saunders; 2003.

53. Höftberger R, Kunze M, Voigtländer T, Unterberger U, Regelsberger G, Bauer J, Aboul-Enein F, Garzuly F, Forss-Petter S, Bernheimer H, Berger J, Budka H. Peroxisomal localization of the proopiomelanocortin-derived peptides ß-lipotropin and ß-endorphin. Endocrinology. 2010;151:4801-10.

54. Veening JG, Barendregt HP. The effects of beta-endorphin: state change modification. Fluids Barriers CNS. 2015;12:3.

55. Nurmikko TJ. Post-herpetic neuralgia: a model for neuropathic pain? In: Hansson PT, Fields HL, Hill RG, Marchettini P, editors. Neuropathic pain: pathophysiology and treatment. Progress in pain research and management, vol. 21. Seattle: IASP Press; 2001. p. 151-67.
56. Dickenson AH, Matthews EA, Suzuki R. Central nervous system mechanisms of pain in peripheral neuropathy. In: Hansson PT, Fields HL, Hill RG, Marchettini P, editors. Neuropathic pain: pathophysiology and treatment. Progress in pain research and management, vol. 21. Seattle: IASP Press; 2001. p. 85-106.

57. Kelley NJ, Schmeichel BJ. The effects of negative emotions on sensory perception: fear but not anger decreases tactile sensitivity. Front Psychol. 2014;5: 942.

58. Klauenberg S, Maier C, Asson HJ, Hoffmann A, Krumova EK, Magerl W, Scherens A, Treede RD, Juckel G. Depression and changed pain perception: hints for a central disinhibition mechanism. Pain. 2008;140:332-43.

59. Kundermann B, Spernal J, Huber MT, Krieg JC, Lautenbacher $\mathrm{S}$. Sleep deprivation affects thermal pain thresholds but not somatosensory thresholds in healthy volunteers. Psychosom Med. 2004;66: 932-7.

60. Pfau DB, Krumova EK, Treede RD, Baron R, Toelle T, Birklein F, Eich W, Geber C, Gerhardt A, Weiss T, Magerl W, Maier C. Quantitative sensory testing in the German Research Network on Neuropathic Pain (DFNS): reference data for the trunk and application in patients with chronic postherpetic neuralgia. Pain. 2014;155:1002-15.

61. Haroutounian S. Somatosensory phenotyping for better translation in neuropathic pain? Pain. 2016;157:995-6. 